\title{
Efficacy of WINROP as a Screening Tool for Retinopathy of Prematurity in the East Coast of Malaysia
}

This article was published in the following Dove Press journal: Clinical Ophthalmology

\author{
Zi Di Lim ${ }^{1,2}$ \\ Kok Tian Ool,2 \\ Evelyn Li Min Tai $\mathbb{D}^{1,2}$ \\ Ismail Shatriah $\mathbb{D}^{1,2}$ \\ 'Department of Ophthalmology, School \\ of Medical Sciences, Universiti Sains \\ Malaysia, Kubang Kerian 16150, Kelantan, \\ Malaysia; ${ }^{2}$ Ophthalmology Clinic, Hospital \\ Universiti Sains Malaysia, Kubang Kerian \\ 16I50, Kelantan, Malaysia
}

Correspondence: Ismail Shatriah

Department of Ophthalmology, School of Medical Sciences, Universiti Sains

Malaysia, Kubang Kerian 16150, Kelantan, Malaysia

Email shatriah@usm.my
Purpose: To evaluate the efficacy of the "weight, insulin-like growth factor 1, neonatal retinopathy of prematurity" (WINROP) algorithm in predicting retinopathy of prematurity (ROP) requiring treatment in Malaysia.

Participants: This was a retrospective study involving premature infants with gestational age less than 32 weeks treated from September 2016 to March 2019 in Hospital Universiti Sains Malaysia. Clinical diagnosis was made based on Early Treatment Retinopathy of Prematurity study. Participants' weekly weight gain since birth was entered in the website (http://winrop.com), along with date of birth, gestational age and final clinical examination outcome. WINROP software signals an alarm if an infant is at high risk of developing ROP requiring treatment during weight data entry. By using the alarm status, the sensitivity and specificity of this algorithm for predicting ROP requiring treatment were obtained.

Results: Ninety-two infants were included in this study. An alarm was detected in 67 infants (72.8\%). There were a total of 53 infants (54.6\%) with no ROP, 15 (16.3\%) of whom developed stage 1 ROP, 10 (10.8\%) who developed stage 2 ROP and 14 infants (15.2\%) who developed stage 3 ROP. In our study, WINROP sensitivity was $95.2 \%$ and specificity was $33.8 \%$.

Conclusion: WINROP is recommended as an initial screening tool for premature infants at risk of developing treatment-requiring ROP in Malaysia. It may help to alert clinicians managing severely ill infants when clinical examinations are less possible.

Keywords: WINROP, retinopathy of prematurity, sensitivity, specificity

\section{Introduction}

"Weight, insulin-like growth factor 1, neonatal retinopathy of prematurity" (WINROP) is an online surveillance system (www.winrop.com) designed to use serial measurements of neonatal body weight to predict the risk of development of retinopathy of prematurity (ROP) requiring treatment. The program compares the weekly weight gain of each infant against an expected weight curve. An alarm is triggered if the sum of the deviation exceeds a predetermined limit, indicating that the infant is at high risk of developing ROP requiring treatment.

The study outcome has been described in numerous countries. ${ }^{1-16}$ In Asia, it has been reported in China, Korea, Taiwan, India and Japan., 6,11,15,16 Based on a PubMed search, no similar reports are available from the South East Asia region, especially in a developing country. This study thus aims to investigate the efficacy of WINROP in the East Coast of Malaysia. 


\section{Materials and Methods}

This was a retrospective study among preterm infants born in Hospital Universiti Sains Malaysia from September 2016 to August 2018. All premature infants with gestational age less than 32 weeks were included. Exclusion criteria included infants with ocular defects, major congenital abnormalities, hydrocephalus and infants who died before their final ROP status was available. Ethical approval was obtained from the Human Research Ethical Committee of the School of Medical Sciences, Universiti Sains Malaysia (USM/JEPeM/18090441). Parental consent was not required as the subjects were anonymized by the use of software-generated identification and the study only used data acquired from routine management of these infants. The conduct of the study was in accordance with the tenets of the Declaration of Helsinki.

According to the ROP guidelines of Malaysia, screening should be carried out for infants with either of the following: (1) Birth weight less than 1500 gram or (2) Gestational age less than 32 weeks or (3) Infants with an unstable clinical course who are at high risk as determined by the neonatologist or pediatrician.

All infants who fulfilled the inclusion criteria were screened. Infants less than 27 weeks gestational age were first screened at 31 weeks, while infants between 27 weeks and 32 weeks were first screened at 4 weeks after birth. Follow up screening of infants with ROP not requiring treatment was weekly, until the retina was fully vascularized. Follow up of infants with no ROP was two- weekly until the retina was fully vascularized. ROP requiring treatment was type 1 ROP, based on the Early Treatment Retinopathy of Prematurity study, as well as type 2 ROP with signs of progression. ${ }^{17}$

Retinal examination was performed after pupil dilation with guttate cyclopentolate $0.5 \%$ using binocular indirect ophthalmoscopy. Type of ROP was recorded using the International Classification of Retinopathy of Prematurity. ${ }^{18}$ Weight was measured using a standardized electric weighing machine for infants.

The access to the website (https://winrop.com) was obtained from the WINROP programmer. Data entered were date of birth, gestational age, weekly weight gain and final ROP examination outcome. To maintain the anonymity of participants, no names were used. The WINROP software would signal an alarm during the course of monitoring if an infant was at high risk of developing ROP requiring treatment.
Descriptive statistics were analysed using Statistical Package for Social Sciences for Windows version 24 (Chicago IL, USA). The sensitivity, specificity, positive and negative predictive value of this algorithm were calculated based on the alarm status in WINROP.

\section{Results}

Ninety-six premature infants who fulfilled the inclusion criteria were included in this study, four of whom were excluded due to premature deaths and hydrocephalus. No infants above 32 weeks were included. An alarm was detected in 67 infants $(72.8 \%)$. There was a total of 53 infants $(57.7 \%)$ with no ROP. Fifteen infants (16.3\%) developed stage 1 ROP, ten (10.8\%) developed stage 2 ROP and 14 infants (15.2\%) developed stage 3 ROP. Of those who developed ROP, 21 infants required treatment (53.8\%); among them, 14 (35.9\%) were type 1 ROP and 7 (17.9\%) were type 2 ROP with early signs of progression. A total of 18 infants $(46.2 \%)$ experienced spontaneous regression of their condition. No infant had an aggressive posterior ROP.

In our study, the mean gestational age was $29.3 \pm 1.7$ weeks and the mean birth weight was 1072.8 \pm 240.2 gram. In contrast, the alarm positive group had a mean gestational age of $27.5 \pm 1.5$ weeks (range 24-32 weeks) and a mean birth weight was 959.6 \pm 192.9 gram (range 550-1380 gram), while in the alarm negative group, the mean gestational age was $29.9 \pm 1.9$ weeks (range 25-32 weeks) and the mean birth weight was $1347.6 \pm 100.8$ gram (range 1140-1490 gram). The results are presented in Tables 1 and 2. WINROP sensitivity in our study was 95.2\% (95\% CI: 74.1-99.7), specificity 33.8\% (95\% CI: $23.2-46.1$ ), positive predictive value $29.9 \%$ (95\% CI 19.6 42.4 ) and negative predictive value $96.0 \%$ (95\% CI 77.6 99.8), as shown in Table 3.

In relation to the timing of alarm, seven out of 21 $(33.3 \%)$ infants requiring treatment had an alarm in week one, while one out of $21(4.8 \%)$ infants had a late alarm, detected at week five. The median time to alarm was 2 weeks from birth while the mode was 1 week from birth. It ranged from birth to 5 weeks post gestational age as shown in Figure 1. No alarms were detected in post-treatment infants.

\section{Discussion}

There are an estimated 15 million infants born prematurely each year. It has been observed that ROP severity and rate differs among countries, with higher rates and more severe 
Table I Demographic Characteristics

\begin{tabular}{|l|l|}
\hline Characteristics & Premature Infants, n (\%) \\
\hline $\begin{array}{l}\text { Gestational Age, Weeks } \\
\text { Mean } \pm S D\end{array}$ & $29.3 \pm 1.7$ \\
Range & $24-32$ \\
\hline $\begin{array}{l}\text { Birth Weight, gram } \\
\text { Mean } \pm \text { SD }\end{array}$ \\
Range & $1072.8 \pm 240.2$ \\
\hline Ethnic & $550-1490$ \\
Malay & \\
Chinese & $87(94.6)$ \\
Indian & $5(5.4)$ \\
\hline Gender & $0(0.0)$ \\
Male & \\
Female & $55(59.7)$ \\
\hline
\end{tabular}

Abbreviations: SD, standard deviation; ROP, retinopathy of prematurity

Table 2 Mean Gestational Age and Birth Weight According to Alarm Status, ROP Requiring Treatment and ROP Staging Based on Clinical Examination

\begin{tabular}{|c|c|c|c|}
\hline Variables & $\mathbf{n}$ & $\begin{array}{l}\text { Mean } \\
\text { Gestational } \\
\text { Age } \pm \text { SD } \\
\text { (Weeks) }\end{array}$ & $\begin{array}{l}\text { Mean Birth } \\
\text { Weight } \pm S D \\
\text { (Gram) }\end{array}$ \\
\hline \multirow{3}{*}{$\begin{array}{l}\text { WINROP Alarm Status } \\
\text { Alarm positive } \\
\text { Alarm negative }\end{array}$} & & & \\
\hline & 67 & $27.5 \pm 1.5$ & $959.6 \pm 192.9$ \\
\hline & 25 & $29.9 \pm 1.9$ & $1347.6 \pm 100.8$ \\
\hline \multicolumn{4}{|l|}{ ROP Requiring } \\
\hline \multicolumn{4}{|l|}{ Treatment } \\
\hline Yes & 21 & $26.3 \pm 1.4$ & $895.5 \pm|8| .7$ \\
\hline No & 71 & $29.8 \pm 1.3$ & $1120.7 \pm 234.8$ \\
\hline \multicolumn{4}{|l|}{ ROP Staging Based on } \\
\hline \\
\hline No ROP & 53 & $29.1 \pm 1.6$ & $1160.6 \pm 216.6$ \\
\hline Stage I & 15 & $27.6 \pm 2.0$ & $947.1 \pm 201.2$ \\
\hline Stage 2 & 10 & $26.8 \pm 2.0$ & $876.0 \pm 201.1$ \\
\hline Stage 3 & 14 & $27.1 \pm 1.6$ & $923.8 \pm 203.3$ \\
\hline
\end{tabular}

Abbreviations: WINROP, weight insulin-like growth factor I neonatal retinopathy of prematurity; SD, standard deviation; ROP, retinopathy of prematurity.

ROP observed in low-/middle-income than high-income countries. This has been attributed to better ROP screening programs and neonatal care in the latter. ${ }^{19}$ Other reasons cited are limited health resources for neonatal care in the former. $^{20}$

An effective screening program is essential to prevent ROP-related blindness. An ideal screening program should not only be sensitive, but also specific, in order to reduce
Table 3 Sensitivity, Specificity, Positive and Negative Predictive Values of WINROP

\begin{tabular}{|l|l|l|l|}
\hline $\begin{array}{l}\text { WINROP } \\
\text { Alarm } \\
\text { Status }\end{array}$ & $\begin{array}{l}\text { ROP } \\
\text { Requiring } \\
\text { Treatment } \\
(\mathbf{n})\end{array}$ & $\begin{array}{l}\text { ROP Not Requiring } \\
\text { Treatment/No ROP } \\
(\mathbf{n})\end{array}$ & $\begin{array}{l}\text { Predictive } \\
\text { Value }\end{array}$ \\
\hline $\begin{array}{l}\text { Alarm } \\
\text { positive }\end{array}$ & 20 & 47 & \\
Alarm \\
negative
\end{tabular}

Abbreviations: WINROP, weight insulin-like growth factor I neonatal retinopathy of prematurity; PPV, positive predictive value; NPV, negative predictive value.

the workload on healthcare personnel while minimizing stressful and potentially life-threatening examinations on premature infants. ${ }^{21,22}$ Improvement of current screening methods will significantly improve the quality of care of these patients. The high negative predictive value of our study, at $96 \%$, suggests that WINROP may be able to reduce unnecessary screening of infants with low risk of developing ROP requiring treatment.

WINROP algorithm is an attractive option for screening as it requires only the gestational age and the weekly weight gain. If the weekly weight gain deviates significantly from the expected gain, an alarm is triggered. This alarm will serve to warn the managing team that the infant is at high risk of developing ROP requiring treatment, thus facilitating appropriate further measures.

Table 4 summarizes the results of 12 countries of both high- and moderate-/low-income status who have participated in the WINROP study, including our study. ${ }^{1-16}$ Overall, WINROP has been reported to have good efficacy as a screening tool. However, the sensitivity of WINROP varies among countries. High-income countries such as Sweden $^{1}$ and $\mathrm{USA}^{3}$ recorded sensitivities of $100 \%$, while middle-income countries like Mexico $^{5}$ and Taiwan ${ }^{11}$ recorded a lower sensitivity; $84 \%$ and $64 \%$, respectively.

In our study, the sensitivity of WINROP to predict infants at high risk of developing ROP requiring treatment was $95.2 \%$, in which it successfully detected 20 out of 21 infants with ROP requiring treatment. This shows that it has a very low false-negative value, suggesting that it has the chance of missing infants who are at high risk of developing ROP requiring treatment is low. This reflects its utility as a ROP screening tool. The only infant in our study whose ROP was missed was born with a birth weight of $1.45 \mathrm{~kg}$, at 31 weeks six days gestational age 


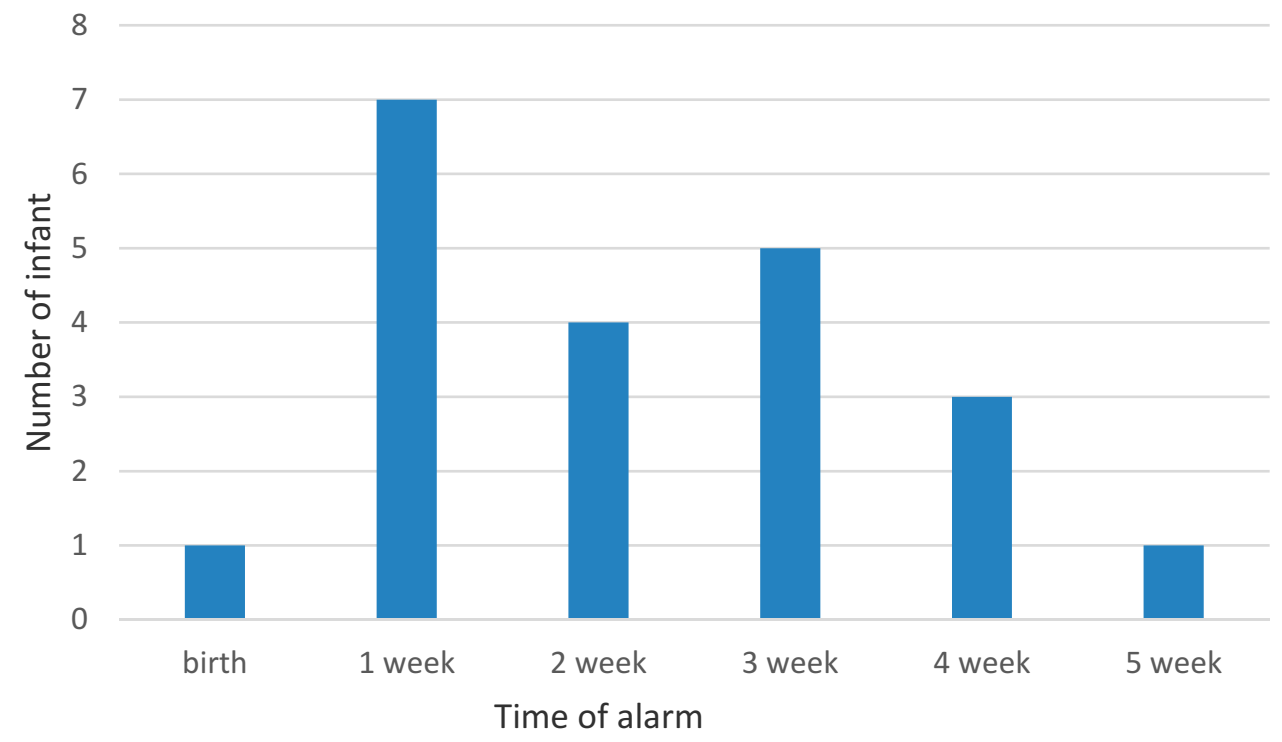

Figure I Distribution of infants requiring treatment in relation to timing of alarm from birth.

and had an average weight gain of 50 grams per week. ROP was detected at 6 weeks of life during routine screening and was treated with laser treatment. Other comorbidities of this infant included respiratory distress syndrome requiring prolonged ventilation, nosocomial sepsis and a large patent ductus arteriosus requiring surgical intervention. The sensitivity of our study is comparable to most developed countries, such as Sweden ${ }^{1}(100 \%)$, Brazil ${ }^{2}$ (90.5\%), USA ${ }^{3}(100 \%)$, Canada ${ }^{4}(98.6 \%)$ and China ${ }^{6}$ (89.3\%). Although many centres choose to observe type 2 ROP, the fact that ours treats both type 1 and type 2 ROP with early signs of progression accounts for the relatively high rate $(22.8 \%)$ of infants with ROP requiring treatment observed in our study.

Alarms were detected in 67 infants. However, only 21 infants required treatment, which reflects a low specificity (33.8\%). This relatively low specificity may result in false alarms. All infants with alarms will still need screening, as the consequences of missing sight-threatening ROP far outweigh the risks of screening. The specificity of WINROP in our study is one of the lowest compared to previous studies and is comparable to Mexico ${ }^{5}$ (26.6\%),

Table 4 Comparison of Our Study with Participating Countries in the WINROP Study (2009-2020)

\begin{tabular}{|c|c|c|c|c|c|c|c|}
\hline Studies & Year & Country & No. of Infants & Sensitivity (\%) & Specificity (\%) & PPV (\%) & NPV (\%) \\
\hline Hellstrom et al ${ }^{\prime}$ & 2009 & Sweden & 353 & 100.0 & 84.5 & 41.0 & NA \\
\hline Hard et $\mathrm{al}^{2}$ & 2010 & Brazil & 366 & 90.5 & 55.0 & 10.0 & 99.0 \\
\hline Wu et $\mathrm{al}^{3}$ & 2010 & USA & 318 & 100.0 & 81.7 & 34.6 & 100.0 \\
\hline Wu et $\mathrm{al}^{4}$ & 2012 & USA and Canada & 1706 & 98.6 & 38.7 & 13.1 & 99.7 \\
\hline Zepeda-Romero et al ${ }^{5}$ & 2012 & Mexico & 352 & 84.7 & 26.6 & NA & NA \\
\hline Sun et $\mathrm{al}^{6}$ & 2013 & China & 590 & 89.3 & 89.0 & 45.9 & 98.8 \\
\hline Choi et $\mathrm{al}^{7}$ & 2013 & Korea & 314 & 90.0 & 52.6 & 21.7 & 97.3 \\
\hline Lundgren et $\mathrm{al}^{8}$ & 2013 & Sweden & 407 & 95.7 & 23.9 & 14.1 & 97.7 \\
\hline Eriksson et al ${ }^{9}$ & 2014 & Sweden & 104 & 100.0 & 58.6 & 10.8 & 100.0 \\
\hline Piyasena et al $^{10}$ & 2014 & Scotland & 410 & 87.5 & 63.4 & 8.8 & 99.2 \\
\hline Ko et $\mathrm{al}^{\prime \prime}$ & 2015 & Taiwan & 148 & 64.7 & 55.0 & 15.7 & 92.3 \\
\hline Kocak et al ${ }^{12}$ & 2016 & Turkey & 223 & 84.3 & 52.8 & 23 & 95.2 \\
\hline Jagla et $\mathrm{al}^{13}$ & 2017 & Poland & 79 & 81.5 & 71.2 & 59.5 & 88.1 \\
\hline Jung et $\mathrm{al}^{14}$ & 2017 & Canada & 483 & 81.8 & 53.3 & NA & NA \\
\hline Sanghi et al ${ }^{15}$ & 2018 & India & 70 & 90.32 & 38.46 & 53.84 & 83.3 \\
\hline Current study & 2020 & Malaysia & 92 & 95.2 & 33.8 & 29.9 & 96.0 \\
\hline
\end{tabular}

Abbreviations: NA, not available; PPV, positive predictive value; NPV, negative predictive value. 
India ${ }^{15}(38.5 \%)$ and $\operatorname{Japan}^{16}(42.7 \%)$. It is interesting to note that WINROP had a lower specificity in most Asian countries compared to Western countries.

WINROP algorithm was originally created in a developed nation, Sweden. Our study population reflects the population of a developing country, with a different ROP epidemiology. The lower specificity in our study may also be attributed to the difference in the expected weight gain curve in our population compared to the Swedish population. It may be possible to design a unique WINROP algorithm for Malaysia and other Asian countries, using a modified normal expected weight gain curve; as previous authors have suggested, differing geographical zones may require individualised algorithms. ${ }^{7,11}$

One possible limitation of our study is that causes of non-physiological weight gain such as excessive body edema may affect the accuracy of the software algorithm. Second, the WINROP is currently used in premature infants less than 32 weeks of gestational age. Clinicians must have a high index of suspicion for infants slightly older than 32 weeks and above who are at risk of ROP due to their other risk factors.

However, the advantages of WINROP, such as its high sensitivity and non-invasiveness, far outnumber its limitations. As ROP is known to be multifactorial, with risk factors including sepsis, prolonged ventilation, intraventricular hemorrhage and blood transfusion, ${ }^{23}$ the predictive value of WINROP may be increased by incorporation of more risk factors in the algorithm.

\section{Conclusion}

WINROP has a high sensitivity rate and is recommended as an initial screening tool for premature infants at risk of developing treatment-requiring ROP in Malaysia. It may alert clinicians who manage severely ill infants, particularly when regular clinical examinations are less possible due to their systemic illnesses.

\section{Acknowledgment}

We would like to extend our gratitude to the staff of the Neonatal Wards, Hospital Universiti Sains Malaysia, Malaysia, for their cooperation and support during data collection.

\section{Disclosure}

The authors report no funding and no conflicts of interest for this work.

\section{References}

1. Hellstrom A, Hard AL, Engstrom E, Niklasson A, Andersson E, Smith L. Early weight gain predicts retinopathy in preterm infants: new, simple, efficient approach to screening. Pediatrics. 2009;123: e638-645. doi:10.1542/peds.2008-2697

2. Hard AL, Lofqvist C, Fortes Filho JB, Procianoy RS, Smith L, Hellstrom A. Predicting proliferative retinopathy in a Brazilian population of preterm infants with the screening algorithm WINROP. Arch Ophthalmol. 2010;128:1432-1436. doi:10.1001/archophthalmol.2010.255

3. Wu C, VanderVeen DK, Hellström A, Löfqvist C, Smith LEH. Longitudinal postnatal weight measurements for the prediction of retinopathy of prematurity. JAMA Ophthalmol. 2010;128:443-447. doi:10.1001/archophthalmol.2010.31

4. Wu C, Löfqvist C, Smith LEH, VanderVeen DK, Hellström A, Consortium W. Importance of early postnatal weight gain for normal retinal angiogenesis in very preterm infants: a multicenter study analyzing weight velocity deviations for the prediction of retinopathy of prematurity. Arch Ophthalmol. 2012;130:992-999. doi:10.1001/ archophthalmol.2012.243

5. Zepeda-Romero LC, Hard AL, Gomez-Ruiz LM, Gutierrez-Padilla JA, Angulo-Castellanos E, Barrera-de-Leon JC. Prediction of retinopathy of prematurity using the screening algorithm WINROP in a Mexican population of preterm infants. Arch Ophthalmol. 2012;130:720-723. doi:10.1001/archophthalmol.2012.215

6. Sun H, Kang W, Cheng X, et al. The use of the WINROP screening algorithm for the prediction of retinopathy of prematurity in a Chinese population. Neonatology. 2013;104:127-132. doi:10.1159/000351297

7. Choi JH, Lofqvist C, Hellstrom A, Heo H. Efficacy of the screening algorithm WINROP in a Korean population of preterm infants. JAMA Ophthalmol. 2013;131:62-66. doi:10.1001/jamaophthalmol.2013.566

8. Lundgren P, Stoltz Sjostrom E, Domellof M, et al. WINROP identifies severe retinopathy of prematurity at an early stage in a nationbased cohort of extremely preterm infants. PLoS One. 2013;8: e73256. doi:10.1371/journal.pone.0073256

9. Eriksson L, Liden U, Lofqvist C, Hellstrom A. WINROP can modify ROP screening praxis: a validation of WINROP in populations in Sormland and Vastmanland. Br J Ophthalmol. 2014;98:946-964. doi:10.1136/bjophthalmol-2013-304617

10. Piyasena C, Dhaliwal C, Russell H, et al. Prediction of severe retinopathy of prematurity using the WINROP algorithm in a birth cohort in South East Scotland. Arch Dis Child Fetal Neonatal Ed. 2014;99:F29-33. doi:10.1136/archdischild-2013-304101

11. Ko CH, Kuo HK, Chen CC, et al. Using WINROP as an adjuvant screening tool for retinopathy of prematurity in southern Taiwan. $\mathrm{Am}$ $J$ Perinatol. 2015;30:149-154. doi:10.1055/s-0034-1376389

12. Kocak N, Niyaz L, Ariturk N. Prediction of severe retinopathy of prematurity using the screening algorithm WINROP in preterm infants. J AAPOS. 2016;20(6):486-489. doi:10.1016/j.jaapos.2016.08.008

13. Jagla M, Peterko A, Olesinska K, Szymonska I, Kwinta P. Prediction of severe retinopathy of prematurity using the WINROP algorithm in a cohort from Malopolska. A retrospective, single-center study. Dev Period Med. 2017;21:336-343.

14. Jung JL, Wagner BD, McCourt EA, et al. Validation of WINROP for detecting retinopathy of prematurity in a North American cohort of preterm infants. $J$ AAPOS. 2017;21:229-233. doi:10.1016/j. jaapos.2017.05.004

15. Sanghi G, Narang A, Narula S, Dogra MR. WINROP algorithm for prediction of sight threatening retinopathy of prematurity: initial experience in Indian preterm infants. Indian $J$ Ophthalmol. 2018;66:110-113. doi:10.4103/ijo.IJO_486_17

16. Ueda K, Miki A, Nakai S, Yanagisawa S, Nomura K, Nakamura M. Prediction of severe retinopathy of prematurity using the weight gain, insulin-like growth factor 1, and neonatal retinopathy of prematurity algorithm in a Japanese population of preterm infants. Jpn $J$ Ophthalmol. 2020;64(2):223-227. doi:10.1007/s10384-019-00709-z 
17. Good WV. Early treatment for retinopathy of prematurity cooperative group. Final results of the Early Treatment for Retinopathy of Prematurity (ETROP) randomized trial. Trans Am Ophthalmol Soc. 2004;102:233-248.

18. International Committee for the Classification of Retinopathy of Prematurity. The international classification of retinopathy of prematurity revisited. Arch Ophthalmol. 2005;123:991-999. doi:10.1001/ archopht.123.7.991

19. Quinn GE. Retinopathy of prematurity blindness worldwide: phenotypes in the third epidemic. Eye Brain. 2016;8:31-36. doi:10.2147/ EB.S94436
20. Adams GGW. ROP in Asia. Eye. 2019. doi:10.1038/s41433-0190620-y

21. Belda S, Pallás CR, de la Cruz J, Tejada P. Screening for retinopathy of prematurity:is it painful? Neonatology. 2004;86:195-200. doi:10. $1159 / 000079542$

22. Mitchell AJ, Green A, Jeffs DA, Roberson PK. Physiologic effects of retinopathy of prematurity screening examinations. Adv Neonatal Care. 2011;11:291-297. doi:10.1097/ANC.0b013e318225a332

23. Hakeem A, Mohamed GB, Othman MF. Retinopathy of prematurity: a study of prevalence and risk factors. Middle East Afr J Ophthalmol. 2012;19:289-294. doi:10.4103/0974-9233.97927
Clinical Ophthalmology

\section{Publish your work in this journal}

Clinical Ophthalmology is an international, peer-reviewed journal covering all subspecialties within ophthalmology. Key topics include: Optometry; Visual science; Pharmacology and drug therapy in eye diseases; Basic Sciences; Primary and Secondary eye care; Patient Safety and Quality of Care Improvements. This journal is indexed on PubMed

Submit your manuscript here: https://www.dovepress.com/clinical-ophthalmology-journal

\section{Dovepress}

Central and CAS, and is the official journal of The Society of Clinical Ophthalmology (SCO). The manuscript management system is completely online and includes a very quick and fair peer-review system, which is all easy to use. Visit http://www.dovepress.com/ testimonials.php to read real quotes from published authors. 